\title{
The utilization of biochemically modified microfibers from grain by-products as reinforcement for polypropylene biocomposite
}

\author{
A. K. Bledzki ${ }^{1}$, P. Franciszczak ${ }^{1}$, A. Mamun ${ }^{2}$ \\ ${ }^{1}$ West Pomeranian University of Technology Szczecin, Faculty of Mechanical Engineering and Mechatronics, Institute of \\ Materials Science, Piastów 19 Avenue, 70-310 Szczecin, Poland \\ ${ }^{2}$ Universität Kassel, Institut für Werkstofftechnik, Mönchebergstr. 3, 34125 Kassel, Germany
}

Received 1 April 2014; accepted in revised form 31 May 2014

\begin{abstract}
The presented research study aims to evaluate microfibers from grain by-products as a substitute for wood flour in wood-thermoplastic composites. Grain husks are an abundant and cheap source of annual, renewable raw material, which besides lignocellulose, may also contain substantial amounts of starch, proteins and fats. These grain residues may negatively affect the mechanical properties of their composites, and generate an odor when decomposition occurs at higher temperatures during plastics processing. Such odors may also be present in the end-product. In order to overcome this drawback, in this research study, a simple and effective enzymatic treatment is proposed. This environmental friendly process removed protein, starch and fats in selective manner. Treated microfibers have shown enhanced thermal stability for ca. $20^{\circ} \mathrm{C}$ at $1 \%$ of weight loss. This correlates with lower amount of odor emission during plastics processing as well as in the final, injection molded parts (25-65\% decrease). The mechanical properties of composites were either preserved, or slightly improved. All results were compared to standard injection molded softwood WPC.
\end{abstract}

Keywords: biocomposites, lignocellulosic microfibers, grain by-products, enzymatic modification, olfactometry

\section{Introduction}

Wood plastic composites (WPC) are the most widespread natural fiber composites (NFC), and have established their place on the market, because of their mechanical properties. Moreover, they are also known for more specific properties, i.e., their lightweight, vibration damping, and blunt fracture. Due to the high freedom of design and the low number of processing steps, WPC have a number of benefits in comparison to components made of wood. They can be processed using extrusion or injection molding, which are both highly efficient methods, and, thus, cost-effective. Furthermore, they meet the sustainability requirements, because they use materials made from raw, renewable resources. This, in turn, contributes to a lower environmental footprint. Their end-products are suitable for recycling, pyrolysis, or can be burned to create energy. These features make them suitable for applications in the automotive, furniture and household industries [1-6].

In recent years, the demand for WPC has risen by about $80000 \mathrm{t} / \mathrm{per}$ annum. New applications for these materials are still being discovered. Annually, approximately 720000 tons of WPC are produced. Approximately 600000 tons are produced in America, about 90000 tons in Asia, and 30000 tons in Europe [7]. However, the shortage of wood, and its rising prices make it necessary to search for substitutes for this raw material [4]. Grain husks or hull by-products from cereal processing are rich in lignocellulose.

\footnotetext{
${ }^{*}$ Corresponding author, e-mail: piotr.franciszczak@zut.edu.pl (C) BME-PT
} 
Current research focuses on their utilization as a substitute for wood.

Wheat (Triticum aestivum) is the most common type of cereal used worldwide, and one of the most important raw materials for the food industry. According to the Food and Agricultural Organization of the United Nations (FAO), its global production reached 671 million tons in 2012, 196 million tons of which were harvested in Europe. Rye crops (Secale cereale) equaled 14.5 million tons worldwide, and approximately 12.7 million tons in Europe. Rice paddy (Oryza sativa) was estimated to 720 million tons, 4.3 million tons of which were harvested in Europe [8]. The brans (hard outer layers of cereal grain) and husks (scaly protective casings of the seeds) comprise varying parts of whole grains depending on a crop's species and variety. Spelt (Triticum spelta) husks used in this research study consist of up to $20-30 \%$ grain $[9,10]$. Similar amounts of husks are in rice paddy, while rye bran is made up of $10-15 \%$ grain [11-13].

Owing to their low nutritional content, wheat and rye brans are usually used as additives in feed. Unfortunately, the outer layers of the grains are exposed to pesticides, or herbicides, and mycotoxins [14]. In the case of hard husks, like rice husks, it is possible to use them as fuel for burning. Although they have a relatively high caloric value, half of which is coal [15], they are rich in silica (ca. 20\%) and other minerals. As a consequence, there are problems concerning the disposal of their volatile ashes [16].

Recently, pilot applications were proposed at paper mills [17]. Another approach focuses on the conversion of lignocellulosic waste materials into bioethanol using enzymes. This process is still being developed, and has encountered some obstacles since lignocellulose consists of many complex polysaccharides so enzymes of combined activities have to be used to break down all the matter into glucose [18-20].

Besides being used as a biomass, they appear to be an appropriate and abundant source for lignocellulose fibers, which can be processed directly after dehusking of the grains. The WPC processors and mills estimate that the price of microfibers prepared from grain by-products is about twice lower than that of microfibers from wood, and the acquisition is simplified. Moreover, they are obtained from annual plants, making them even more sustainable than wood fibers processed from trees [21-23]. The only obstacle which may arise is caused by the contamination of husks with starch, proteins and fats from grain rests. These chemical compounds are less temperature-stable, and lead to the deterioration of the fiber-to-matrix bond. In this case, enzymatic treatment with appropriate hydrolases can remove these unwanted compounds without damaging the cellulose structure. In the case of enzymatic treatment of grain by-products, complexity of multi polysaccharide structure of lignocellulose, thus its resistance to enzymatic breakdown can be favorable when desiring to preserve its chemical structure. Some research has already been done in the field of enzymatic treatment of natural fibers of bast or leaf origin. In those cases, mainly pectinase was used to improve the fibrillation, and remove waxes attached by pectins to the outer cell walls. Modest improvements have been achieved in comparison to traditional methods. The so-called bio-scouring process is currently still under development, also in large companies [24-26].

The presented research study focuses on the manufacture of natural fiber composites reinforced with microfibers from spelt and rice husks and rye brans, which are common cereals in Europe and Asia. The husk and brans were ground to smaller fibrous particles, and, subsequently, enzymatically treated prior to pellet manufacturing by compounding them with a polymer matrix and compatibilizer. These composites are oriented to processing by means of injection molding. Fine particle sizes were chosen, which enable an easy melt flow, and which help to avoid impact cracking typical for the composite reinforced with coarse particle sizes. The enzymatic treatment proposed in the course of this research is necessary for all applications of these biocomposites where odor emission can exclude them from usage - these are furniture, housing and automotive parts.

The results found for the properties of the natural fiber composites reinforced with microfibers were compared with standard, injection molded, softwood reinforced WPC that was modified and processed in the same way.

\section{Materials and methods \\ 2.1. Materials}

Injection molding grade polypropylene HP400R of Bassel-Orlen, Poland, was used as a matrix. This homopolymer exhibits good stiffness and high fluidity of MFR $=25$ and $\mathrm{MVR}=34\left(230^{\circ} \mathrm{C} / 2.16 \mathrm{~kg}\right)$. 
Microfibers used as reinforcement were prepared at the Institute für Lebensmittel und Umweltforschung, Potsdam, Germany, by conditioning and milling spelt (Triticum spelta) and rice husks (Oryza sativa) and rye brans (Secale cereale) into particles sizes smaller than $600 \mu \mathrm{m}$. For reference purposes, microfibers made of the industrial grade softwood flour Jeluxyl Weho500 by Jeluwerk, Germany were used. Jeluxyl Weho500 consists of a mix of European spruce (Picea abies) and silver fir (Abies alba). A matrix-to-fiber weight ratio of $60 / 40$ was used for all composites.

Three types of enzyme hydrolases were used to remove starch, protein and fat residues from the microfibers, namely alpha-amylase, protease and lipase. The commercial grade enzymes provided by Novozymes, Denmark are listed in Table 1. The alpha-amylase, lipase and protease employed were designed to be used in washing processes, which is why they have broad $\mathrm{pH}$ and temperature spectrums. Moreover these products have improved thermal stability.

Maleic acid anhydride grafted PP wax (MAH-g-PP) TP Licocene PP MA 6452 from Clariant, Germany of $3.3 \mathrm{wt} \%$ in relation to the matrix was applied as a compatibilizer between a non-polar matrix and polar lignocellulosic fibers.

\subsection{Methods}

\subsubsection{Enzymatic treatment of microfibers}

The enzymatic treatment was performed in order to remove unwanted constituents from the microfibers. Fats, proteins and starch dust may remain on the grain during the dehulling and dehusking processes. Most of these low molecular weight compounds, especially lipids and proteins, decompose at lower temperatures than cellulose and hemicellulose (at approximately $200^{\circ} \mathrm{C}$ ). Consequently, they undergo degradation during compounding and injection molding [27]. This tends to weaken the fiber/matrix interface, and causes the emission of volatile degradation products, which, in turn, increase the odor of the material significantly while darkening the color of the material. Enzymatic treatment ensures the selective hydrolysis of unwanted compounds to water soluble dextrins (from starch), amino acids (from proteins) and fatty acids and glycerol (from lipids) without damaging the structure. Moreover, the carbon footprint is extremely small [28].

The mixture of three different type of enzymes consisted of lipase, protease and alpha-amylase. Additionally, hemicellulase, namely Pulpzyme HC, was used in order to roughen the surface of the microfibers, and facilitate the removal of the starch, lipids and proteins from the surface of the input material. The citrate sodium hydroxide buffer was added to maintain the $\mathrm{pH}$ level. The use of sodium hydroxide is substantial for the hydrolysis of lipids to glycerol and fatty acids. They react with one another, and produce sodium soap which simultaneously wets the fats, and, therefore, facilitates the degradation of the lipids to a large extent.

The whole process profile of the enzymatic treatment is presented in Figure 1. The microfibers were added to distilled water in a 1:8 ratio, and stirred constantly throughout the entire treatment with enzymes. In the beginning, the $\mathrm{pH}$ level was set at 7 to work at the optimum level for Pulpzyme HC. In the first stage, Pulpzyme HC (xylanase) was added to the suspension together with Lipex 100L (lipase) and Termamyl 300L (alpha-amylase). Each added enzyme portion equaled $1 \mathrm{~mL}$. This stage took

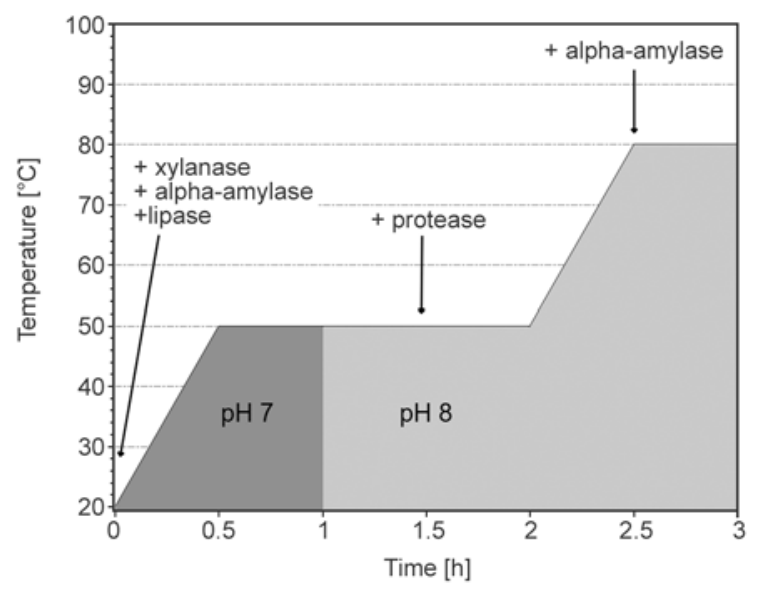

Figure 1. Process profile of enzymatic treatment

Table 1. Enzymes used in the processing of microfibers

\begin{tabular}{|l|l|c|c|l|}
\hline \multicolumn{1}{|c|}{ Trade name } & Chemical name & $\mathbf{p H}$ range & $\begin{array}{c}\text { Temperature range } \\
{\left[{ }^{\circ} \mathbf{C}\right]}\end{array}$ & \multicolumn{1}{c|}{ Type of reaction } \\
\hline Termamyl 300L & Alpha-amylase & $6.5-9.5$ & $20-90$ & Hydrolysis of $\alpha-1,4$-bonds of amylose and amylopectin \\
\hline Alcalase 2.5L & Protease & $7-10$ & $10-65$ & Broad spectrum of peptide bond hydrolysis \\
\hline Lipex 100L & Lipase & $7-11$ & $20-60$ & Hydrolysis of carboxylic esters \\
\hline Pulpzyme HC & Xylanase & $6-8$ & $50-60$ & $\beta-1,4$ xylanase activity \\
\hline
\end{tabular}


approximately $30 \mathrm{~min}$ to complete, and was finished when suspension reached $50^{\circ} \mathrm{C}$. It was kept at this temperature for the ensuing half hour.

In the second stage of the process, the $\mathrm{pH}$ level was set to 8 , in order to be closer to the activity optimum of the rest of the enzymes. This level was maintained for half an hour before protease (Alcalase $2.5 \mathrm{~L}$ ) was added to hydrolyze the proteins. The same conditions as before were used for another half hour to let it react in optimal conditions. Protease induces degradation in other enzymes, so it was deactivated by increasing the temperature of the suspension to $80^{\circ} \mathrm{C}$ for the next 30 minutes.

In the third stage of the enzymatic treatment, the diluted crystalline starch was completely hydrolyzed to dextrose by adding a second dose of Termamyl $300 \mathrm{~L}$, which is a thermally stable alpha-amylase. Throughout the whole process, the concentration of the entire enzyme solutions equaled ca. $0.0625 \mathrm{wt} \%$. After the enzymatic treatment, the fibers were rinsed with water to flush out the products of enzymatic hydrolysis.

In order to extend the previous research done by Mamun and Bledzki [29], the Weho500 (reference material) was also treated to evaluate the possibility of fiber damage during enzymatic treatment.

\subsubsection{Characterization of microfibers}

Chemical composition of microfibers

All chemical compositions of grain by-products were measured according to the official method of analysis of AOAC International (AOAC methods, 2007). The analytical results were measured twice, their standard deviation equaled $5 \%$.

Cellulose, hemicellulose and lignin contents:

Neutral detergent dietary fiber (NDF), acid detergent dietary fiber (ADF) and acid detergent lignin (ADL) contents were measured using the Van Soest chemical method $[1963 ; 1967]$ with modifications made by McQueen and Nicholson [1979]. Modification relied on the application of the alpha-amylase, in order to successfully degrade the starch. Dietary fiber was isolated by means of detergent solutions of acidic and neutral $\mathrm{pH}$. Hot extractions of samples were carried out on a Fibertec apparatus produced by Foss Tecator (Sweden). The hemicellulose fraction was calculated on the basis of the NDF and ADF difference, while the cellulose fraction was calculated using the difference between ADF and ADL.
Starch contents:

The starch content was determined according to PN-R-64785:1994. This method relies on the dissolution of a sample material using hydrochloric acid, and measuring of specific rotation of light in clear extract using polarimeter.

\section{Protein contents:}

The protein content was determined using the Kjeldahl method, which involves the mineralization of samples using concentrated sulphuric acid. Subsequently, the amount of ammonia produced in the reaction is measured. In order to convert the nitrogen content to the protein content, the factor 6.25 was applied in accordance to PN-EN ISO 20483. This was carried out on a Kjeltec device setup by Foss Tecator (Sweden).

Fat content:

The fat content was determined according to PN-64/ A74039 using a method of multiple extraction of samples with petroleum ether. After the ether evaporated, the remaining fat was weighed. A Soxtec HT6 setup by Foss Tecator (Sweden) was used was used to extract samples.

\section{Thermal gravimetric analysis}

The thermal gravimetric analysis (TGA) was carried out using the thermal gravimetric analyzer Q5000 by TA Instruments, USA. Samples were dried for $2 \mathrm{~h}$ at $103^{\circ} \mathrm{C}$ in the TGA chamber to evaporate all the moisture, and were then heated $5^{\circ} \mathrm{C} / \mathrm{min}$. Tests were performed in an air medium.

\section{Particle geometry evaluation}

The aspect ratio was measured using a static 2-D microscopy method which employs a Morphologi G3 device produced by Malvern, UK. The test samples were prepared in a dry powder dispersion to ensure that all particles were separated from each other. 50-100 thousand particles were measured for each batch of material. For each particle the aspect ratio and surface area (converted to spherical equivalent volume) was measured. These data were used to calculate the volumetric average aspect ratio.

\subsection{Manufacturing of composites 2.3.1. Compounding}

Microfibers were dried prior to compounding in an SLW115 of POL-EKO, Poland - oven with forced 
convection (approx. $16 \mathrm{~h}$ at $103^{\circ} \mathrm{C}$, moisture content $<0.3 \mathrm{wt} \%$ ). PP was processed without drying. The pre-dried microfibers were compounded with PP and MAH-g-PP granulates using a Laborextruder LSM30 manufactured by Leistritz, Germany (counter-rotating, tightly intermeshing twin-screw extruder, $L / D=23, D=34 \mathrm{~mm}$ ). The extruded strand was cooled in a water bath, and pelletized. The materials were compounded at temperatures ranging from 170 to $190^{\circ} \mathrm{C}$, and at $40 \mathrm{rpm}$. The processing method ensured a good fiber distribution and an even fiber-to-matrix ratio, as is visible in the results of the density measurements and the small deviations in the mechanical properties for each manufactured type of composite material.

\subsubsection{Injection molding}

The standard test specimens manufactured according to EN ISO 178 were injection molded using an ALLROUNDER 270 S 350-100 produced by ARBURG, Germany, (clamping force $350 \mathrm{kN}$, screw diameter $25 \mathrm{~mm}, L / D=20$ ) and was provided by PRACHT GROUP Company. The molds adhere to EN ISO 294-1, type B. The barrel temperatures were $165-200^{\circ} \mathrm{C}$ from the feed zone to the nozzle. The injection pressure was limited to 800 bar at a constant injection speed of $20 \mathrm{~cm}^{3} / \mathrm{s}$, resulting in actual injection pressures ranging from 450 to 550 bar.

\subsection{Characterization of composites}

\subsubsection{Density measurement}

The density of the manufactured composites was measured using the Archimedes method at room temperature on a high accuracy scale type AS made by Radwag, Poland, according to EN ISO 1183. Samples were measured in ethanol medium. Weighing was repeated three times and the average of the measured values was calculated.

\subsubsection{Odor measurement}

The odor concentration was measured in accordance with EN ISO 13725 using a human nose as a sensor. The samples were put in an environment tempered to $70^{\circ} \mathrm{C}$ for $6 \mathrm{~h}$ in order to increase the emission from samples, and to simulate the extreme conditions which may occur during exploitation in closed, nonventilated chambers. The dynamic, half-automatic, pneumatic olfactometer type TO7, ECOMA, Germany was used for the purpose of measurements.

\subsubsection{Flexural test}

The static mechanical properties of the manufactured test specimens were measured in a flexural test according to EN ISO 178. The test was carried out on an universal testing machine type 3366, Instron, UK. The testing parameters were as follows: $1 \mathrm{~mm} / \mathrm{min}$ for the estimation of the flexural $E$-modulus, and $2 \mathrm{~mm} / \mathrm{min}$ for the estimation of the tensile strength. The following values represent the averaged results of the measurements performed on 10 samples for each type of composite material.

\subsubsection{Notch impact strength}

The impact strength was tested using the Izod method according to EN ISO 180/A on a Typ B5102 apparatus by Zwick, Germany. The A-notch was prepared on specimens using a dedicated notching machine. All composites were tested at room temperature $23^{\circ} \mathrm{C}$ and while subject to $50 \pm 10 \%$ relative humidity. The values presented comprise the averaged results for 10 tests carried out for each type of composite.

\subsubsection{Heat deflection temperature}

The heat deflection temperature (HDT) analyses were conducted on a Vicat-HDT analyzer manufactured by Donserv, Poland, according to EN ISO 75-1. The specimens were analyzed using a bending force of $1.8 \mathrm{MPa}$, a heating rate of $2^{\circ} \mathrm{C} / \mathrm{min}$, and the HDT was measured at a fixed elongation of $2 \mathrm{~mm}$.

\subsubsection{Brightness measurement}

The injection molded samples were scanned using a standard Officejet Pro 8600, HP, USA. The allowance for coloration change was taken by subtraction of scanned white background. Coloration was averaged for 1 square centimeter using GIMP software. The results were presented after calculating the average of the RGB color model values.

\section{Results and discussion \\ 3.1. pH of microfibers}

The $\mathrm{pH}$ of microfibers (Figure 2) after enzymatic treatment rose to neutral due to the buffering process. This can be advantageous for the long-term behavior of composites. It may also be favorable to reinforce polyester matrices that are prone to faster depolymerization in an acidic environment. 


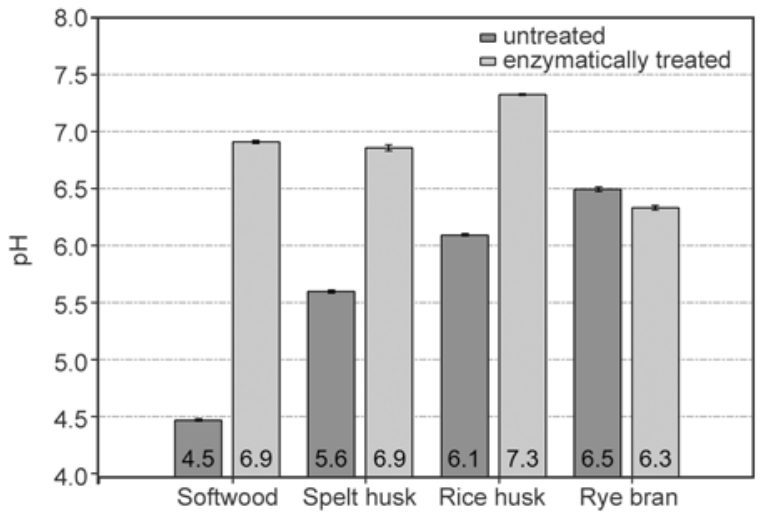

Figure 2. $\mathrm{pH}$ of microfibers before and after enzymatic treatment

\subsection{Chemical composition of microfibers}

In natural fibers, crystalline cellulose micro-fibrils are embedded into an amorphous hemicellulose matrix encrusted with lignin that cross-links these polysaccharides. Therefore, the cellulose content and arrangement of the micro-fibrils is a decisive factor for the physical properties. Microfibers from grain husks have similar amounts of lignocellulosic compounds as standard softwood (Figure 3). Therefore, it is possible to assume that they may have similar reinforcing potential as standard wood fibers in WPC. Husks and, in particular, brans that cover the grains also consist of small amounts of starch, protein and fat. These components can also accumulate in form of particles on the surface of the grains during dehusking and dehulling processes that take place in the mills. In Figure 3 and Table 2, it is visible that the enzymatic treatment of the microfibers from husks and brans reduced the amount of starch approximately three-fold. The decrease of the protein content was most noticeable for microfibers made from spelt husks $(60 \%)$, rice husks $(35 \%)$ and rye brans $(20 \%)$. The fats, which were already made up the smallest content in softwood microfibers, were almost completely removed. Significant reductions were obtained for microfibers from spelt husks

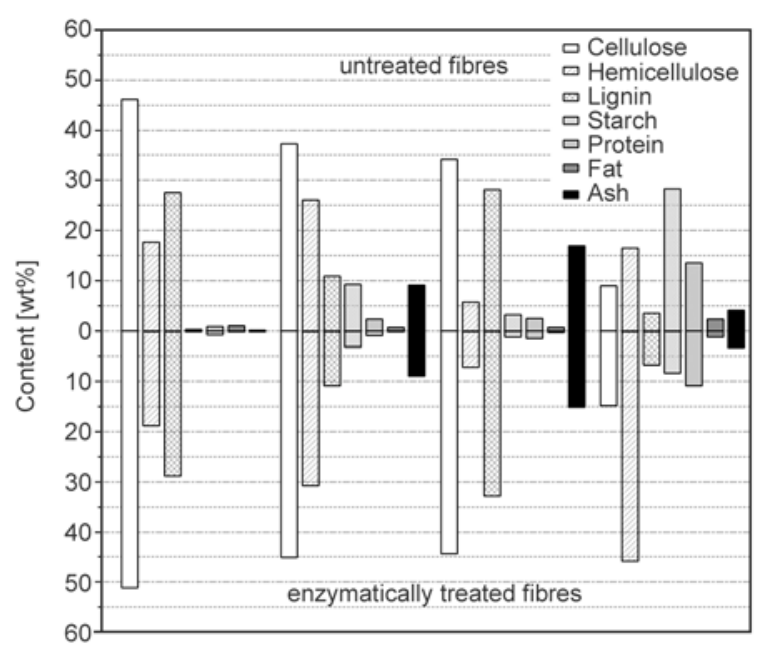

Figure 3. Chemical composition of microfibers before and after the enzymatic treatment

$(60 \%)$, rice husks $(35 \%)$ and rye brans $(45 \%)$. It can be also concluded that brans contain much lower amounts of cellulose than husks, which, in turn, makes them useless as a reinforcing material in composites. Consequently, they can only be applied as a filler.

\subsection{Thermal gravimetric analysis}

The weight loss of microfibers in correlation with temperature is illustrated in Figure 4. The diagram depicts the weight loss of up to $1 \mathrm{wt} \%$ of the initial value, which shows the beginning of the decomposition of microfibers. Figure 4 clearly verifies the achievement presented in Figure 3 and Table 2, namely that the enzymatic treatment considerably reduced the amounts of proteins and fats and, thus, improved the thermal stability of the microfibers. In the case of spelt and rice husks, the thermal stability was even higher than in the case of the reference softwood. In the case of all enzymatically treated microfibers, an initial weight loss of $1 \%$ was detected at approx. $20^{\circ} \mathrm{C}$ higher temperatures than for the untreated counterparts. This achievement is of significant value for thermoplastic composites pro-

Table 2. Chemical composition of microfibers [\%]

\begin{tabular}{|l|c|c|c|c|c|r|r|r|}
\hline & Softwood & $\begin{array}{c}\text { Softwood after } \\
\text { treatment }\end{array}$ & Spelt & $\begin{array}{c}\text { Spelt after } \\
\text { treatment }\end{array}$ & Rice & $\begin{array}{c}\text { Rice after } \\
\text { treatment }\end{array}$ & Rye & $\begin{array}{c}\text { Rye after } \\
\text { treatment }\end{array}$ \\
\hline Cellulose & 46.1 & 51.2 & 37.2 & 45.1 & 34.2 & 44.4 & 8.9 & 14.9 \\
\hline Hemicellulose & 17.7 & 18.8 & 26.0 & 30.8 & 5.7 & 7.1 & 16.5 & 45.8 \\
\hline Lignin & 27.6 & 28.9 & 10.8 & 10.8 & 28.1 & 32.8 & 3.5 & 6.7 \\
\hline Starch & 0.2 & 0.1 & 9.2 & 3.2 & 3.2 & 1.2 & 28.3 & 8.3 \\
\hline Protein & 0.8 & 0.8 & 2.3 & 0.9 & 2.5 & 1.6 & 13.5 & 10.9 \\
\hline Fat & 0.9 & 0.2 & 0.6 & 0.2 & 0.6 & 0.4 & 2.3 & 1.3 \\
\hline Ash & 0.1 & 0.1 & 9.1 & 8.9 & 16.9 & 15.2 & 4.0 & 3.3 \\
\hline
\end{tabular}




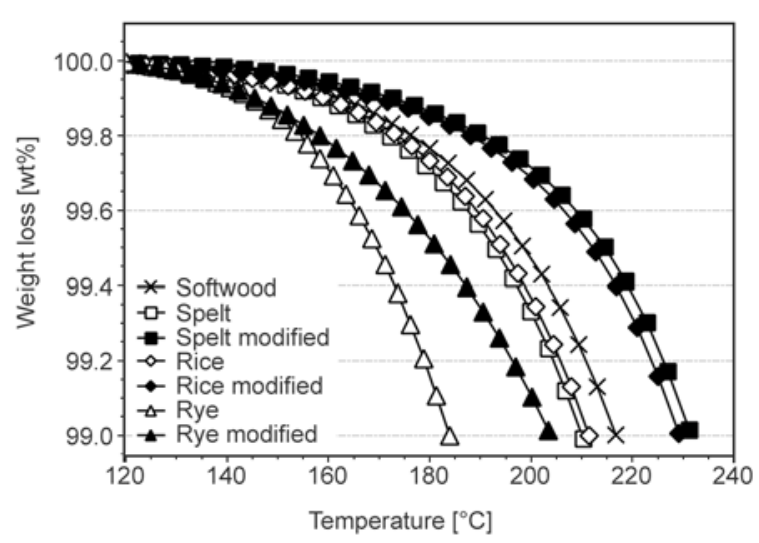

Figure 4. TGA curves of untreated and enzymatically treated microfibers

cessing, because the materials are subject to high pressures and temperatures which induce degradation of the low molecular weight compounds (proteins, fats) leading to deterioration of composite properties, odor emission and darkening of natural hue [30].

\subsection{Aspect ratio of microfibers}

Grain husks and brans were ground into particles sizes similar to those used for the reference softwood fibers, namely $<600 \mu \mathrm{m}$. This particle size ensures that the melted composite material flows better during injection molding, and, therefore, enables injection molding of thin-walled parts. A 2D static analysis revealed that the reference material has a higher aspect ratio than microfibers from grain by-products (Figure 5). Higher aspect ratios provide better fiber-to-matrix stress transfer. This was verified in the results of flexural strength tests (Figure 8), where a correlation between a higher aspect ratio and flexural strength is evident. Microfibers from spelt husks had the highest aspect ratio of all used microfibers from grain husks. Microfibers

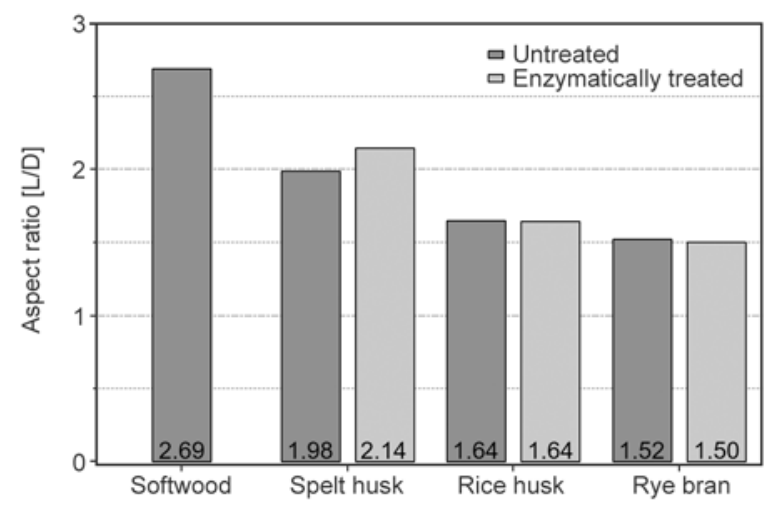

Figure 5. Aspect ratio of untreated and enzymatically treated microfibers from spelt husks had slightly higher aspect ratios, but since enzymes only work on the surface, to the higher aspect ratio can be attributed to the rinsing process instead of the enzymatic treatment itself, because it removed some of the finest particles.

\subsection{Bulk density of microfibers}

The bulk density (Figure 6), which depends upon the fiber shape and chemical composition, confirmed that softwood have the most fibrous geometry among the investigated materials (Figure 5). In the case of softwood and spelt microfibers, it became clear that the rinsing phase of the enzymatic treatment may cause the finest particles to be flushed out, and, therefore, may contribute to increasing the portion of microfibers with a higher aspect ratio which remain after processing. Rice microfibers tend to be the heaviest due to their high silica content and lower aspect ratio. The microfibers from rye brans have a much lower bulk density after enzymatic treatment, which can be explained by the removal of starch and proteins. The remaining lignocellulosic particles are flake-shaped.

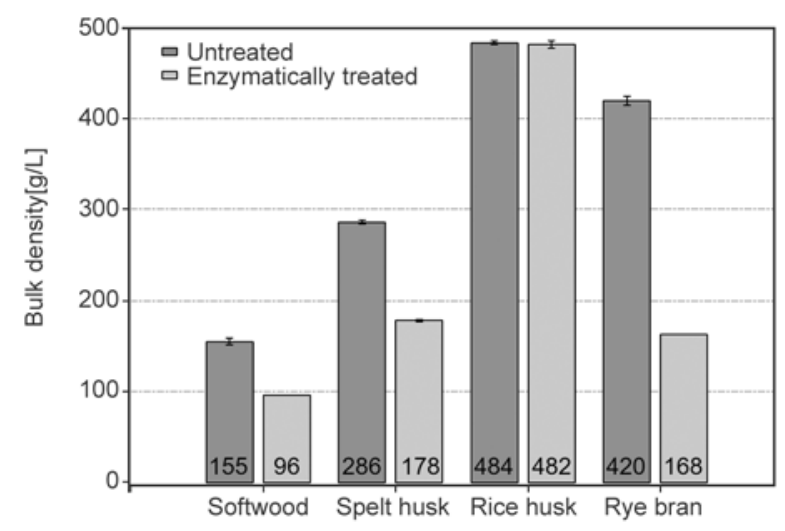

Figure 6. Bulk density of microfibers before and after enzymatic treatment

\subsection{Density of biocomposites}

Microfibers from grain by-products and softwood mainly consist of lignocellulose, thus, their density is similar. Accordingly, all manufactured composites reinforced with the above mentioned microfibers have shown density values in nearly the same range $1.05-1.07 \mathrm{~g} / \mathrm{cm}^{3}$. In contrast, the density of the PP matrix equals $0.91 \mathrm{~g} / \mathrm{cm}^{3}$.

The PP/GF density ranges between $1.03-1.22 \mathrm{~g} / \mathrm{cm}^{3}$ for standard fiber concentrations of $20-40 \mathrm{wt} \%$. In the case of fiber concentrations of $40 \mathrm{wt} \%$, this corresponds to a weight reduction of approx. $15 \%$ in 


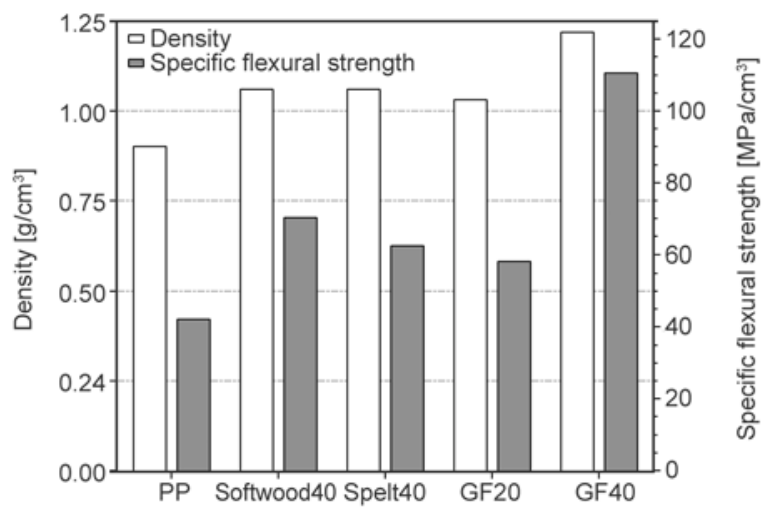

Figure 7. Density and specific flexural strengths of PP, WPC$40 \mathrm{wt} \%$ microfibers (Softwood and Spelt husk), PP-GF20 wt $\%$ and PP-GF40 wt $\%$ [31]

favor of lignocellulosic fibers. When comparing PP reinforced with $20 \mathrm{wt} \%$ GF to PP reinforced with $40 \mathrm{wt} \%$ of softwood, it is visible that an approx. $20 \%$ higher flexural strength of WPC can be achieved while obtaining a density which is only $3 \%$ higher. The light-weight potential of WPC composites and possibility of their complete energetic recyclability are essential features which account for their usage in automobiles and all applications where a reduction of mass is needed. Figure 7 illustrates densities and specific flexural strengths of native PP and its composites with $40 \mathrm{wt} \%$ softwood and spelt husk microfibers as well as 20 and $40 \mathrm{wt} \%$ glass fibers (GF).

\subsection{Mechanical properties}

\subsubsection{Flexural test}

The Stress-strain curves presented in Figure 8 were measured in the flexural tests after averaging the 10

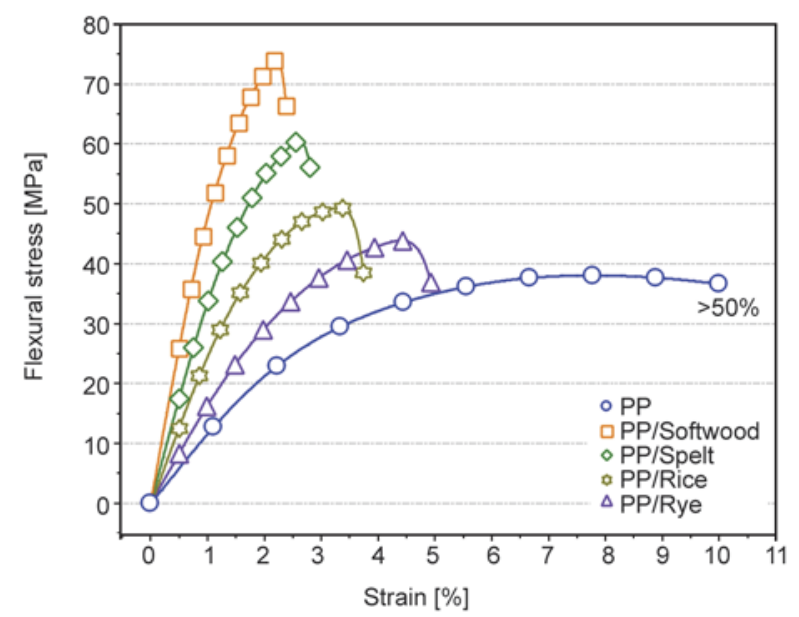

Figure 8. Flexural stress-strain curves of PP biocomposites reinforced with $40 \mathrm{wt} \%$ softwood and enzymatically treated microfibers from grain by-products that were compatibilized with MAH-g-PP specimen curves for each material. The addition of softwood and spelt microfibers changed the material characteristics of the PP matrix from elastic to tough and less ductile. Reinforcing PP with microfibers leads to a visible decrease in strain. However, this is not exceedingly problematic, since a high ductility in not required in most engineering applications for composites. When comparing the curves of PP/Softwood and PP/Spelt, which have fibers with a similar chemical composition, it can be easily concluded that their geometry influences the mechanical properties of their composites. The higher aspect ratio of softwood fibers enabled an improved transfer of stresses from the matrix to the fiber, and, thus, higher strengths.

Figure 9 illustrates the flexural strength of PP and its biocomposites reinforced with microfibers. Flexural strength of PP can almost be doubled using standard softwood microfibers. The microfibers from spelt husks used in this study also resulted in an improvement of the flexural strength by approximately $74 \%$ for untreated and $58 \%$ for enzymatically treated ones. Both untreated and treated microfibers from rice husks increased the flexural strength by only $29 \%$. The rye brans with their low cellulose content also did not contribute to a noticeable improvement. The results clearly show that a coupling between the non-polar matrix and polar fibers must be performed in order to obtain good reinforcement of PP using lignocellulosic fibers. Although this can be done using different methods and types of coupling agents, the use of MAH-g-PP waxes remains the most effective and simple. There is also an evident correlation between the volumetric average aspect ratio of the microfibers (Figure 5) and the flexural strengths of their biocomposites (Figure 8, 9).

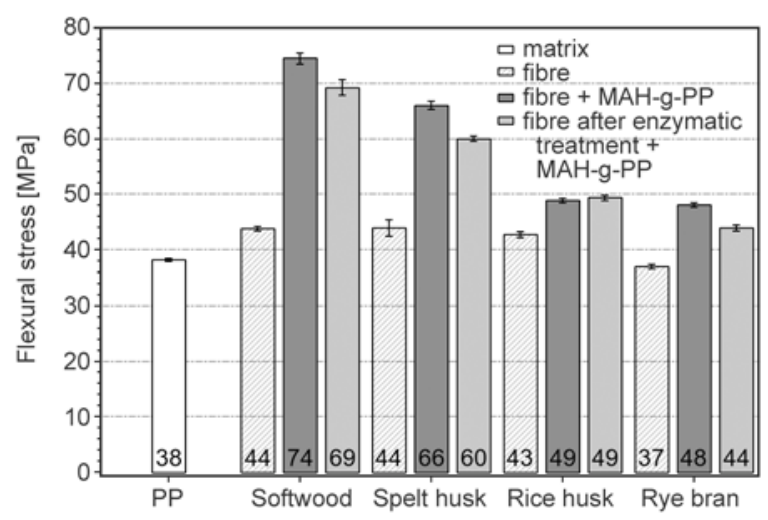

Figure 9. Flexural strength of PP biocomposites 


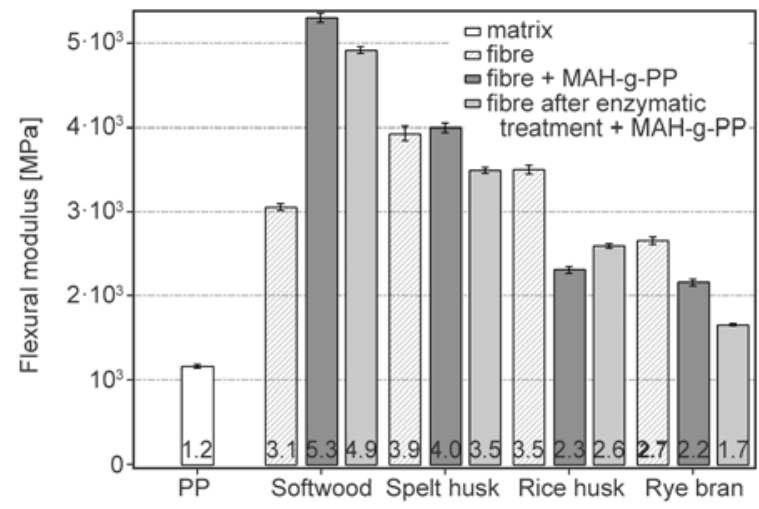

Figure 10. Flexural modulus of PP biocomposites

The flexural moduli of PP composites are illustrated in Figure 10. Here, the stiffness of the composites is not as strongly connected to the constraint of the matrix deformation. This depends on the stiffness of the fibers, their geometry and volume content in the composite, and, to some extent, on a good transfer of stresses from the matrix to the fiber. The obtained results clearly show that softwood microfibers help to improve the stiffness three-fold, and, without the application of MAH-g-PP, to almost five-fold the original value when coupling is applied. This parameter was increased for microfibers from spelt husks approximately four-fold. Here, no discernible difference was identified concerning the use of coupling and enzymatic treatment. Similarly, coupling and enzymatic treatment did not have any influence on the stiffness of composites filled with microfibers taken from rice husks and rye brans.

\subsubsection{Notch impact strength}

The crack propagation resistance evaluated in the notch Izod test, which is presented in Figure 11, was improved from 26 to $13 \%$ for composites reinforced

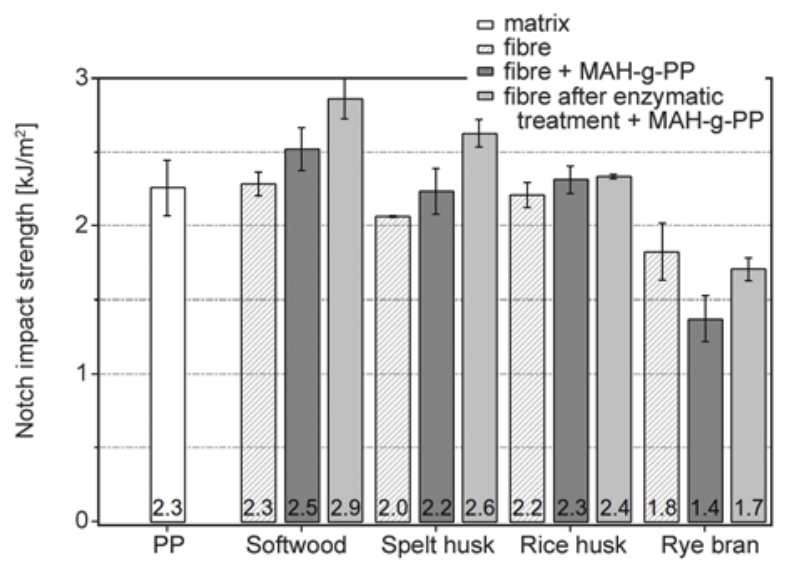

Figure 11. Notch impact strength of PP biocomposites in Izod test with enzymatically treated softwood and spelt husk microfibers. It is a well-known fact that in order to increase the crack propagation resistance, fibers of an appropriate length must be used as reinforcement. The enzymatic treatment led to a slight improvement in impact strength compared to untreated microfibers. This might have been caused either by roughening the microfiber surface using xylanase, or by a higher aspect ratio of treated microfibers which resulted from flushing out finer particles during the rinsing stage of the enzymatic treatment process. In the case of microfibers with a low aspect ratio, they do not increase fracture surface area, and are not tough enough to absorb much energy, so the values of the impact strength can only be preserved or deteriorated.

\subsection{Heat deflection temperature}

Figure 12 shows that the creep under loading at higher temperatures can be significantly decreased. The heat deflection temperature was increased by the factor two for biocomposites with microfibers from spelt husks, and was only approximately $10^{\circ} \mathrm{C}$ lower than for the reference WPC material reinforced with softwood flour. Biocomposites reinforced with enzymatically treated microfibers exhibited slightly better performance. For microfibers from softwood a $12 \%$ increase was recorded, for those from spelt husks a 5\% increase was achieved. Rice husks and rye brans, however, showed no improvement.

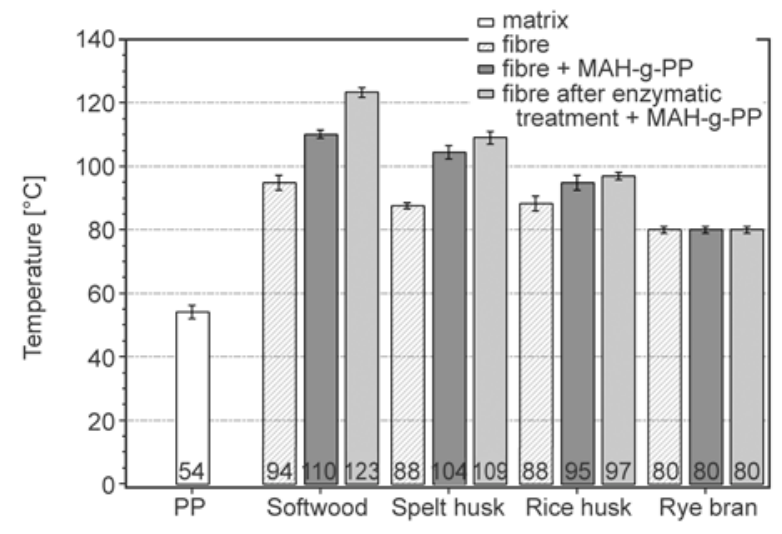

Figure 12. Heat deflection temperature of biocomposite materials

\subsection{Olfactometry}

The results of odor concentration measurements are presented in Figure 13. The most noticeable decline in odor emission for biocomposites with enzymati- 


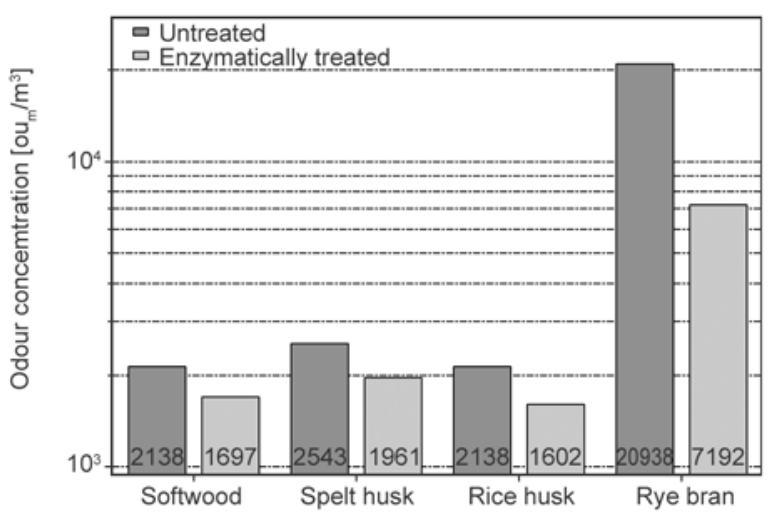

Figure 13. Odor concentration of biocomposites filled with untreated and enzymatically treated fibers

cally treated fibers was reported for rye bran (more than two-fold); other microfibers also exhibited a decent decrease in odor emission. This confirmed the previously obtained results for the chemical composition investigation (Figure 3 ). Odor emission is noticeable at temperatures exceeding $50^{\circ} \mathrm{C}$, and can be an important factor in automotive and furniture applications. Composites which exhibit unacceptably high emission rates despite otherwise good properties can be excluded from these kinds of applications. Thus, the enzymatic treatment of microfibers enables the application of grain husks instead of wood in WPC, making it possible to use them in the very same applications.

\subsection{Brightness improvement}

Treatment with enzymes led to significant increase in brightness of the microfibers. This, in turn, increased the brightness of injection molded parts. This can be important in the case of a lower pigment demand for in melt colorizing of final product, which helps to lower prices of end-product. The best results presented in Figure 14 and Figure 15 were obtained for microfibers from spelt husks. The removal of proteins and fats from the surface of

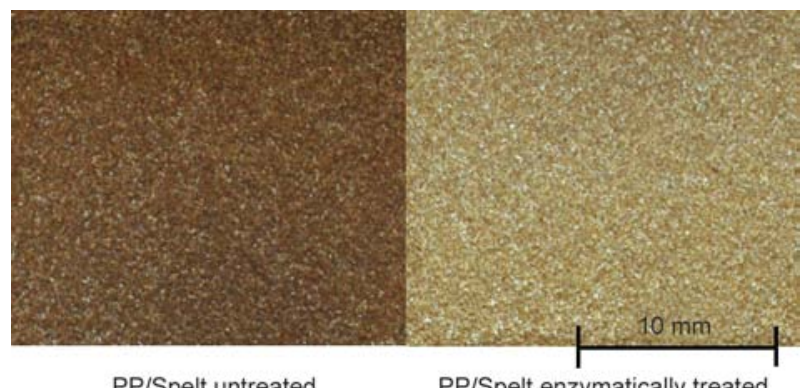

Figure 14. Brightness of biocomposites filled with untreated and treated spelt husk fibers

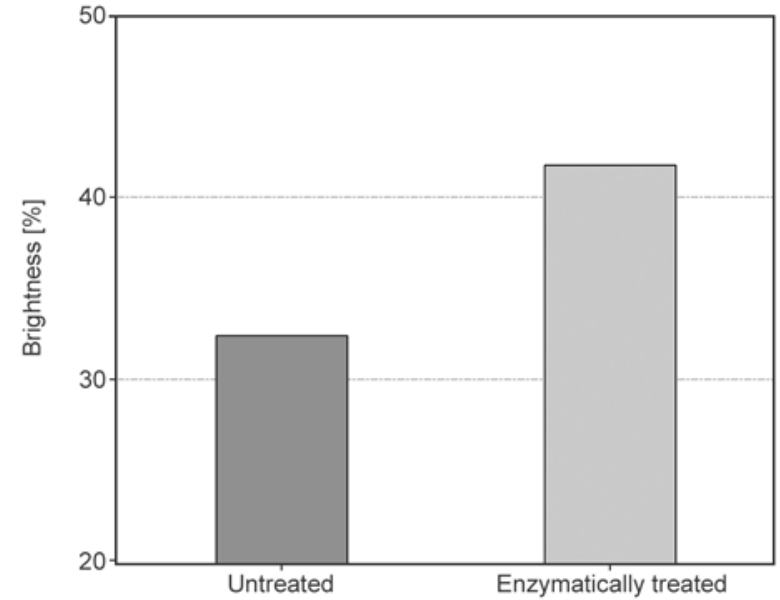

Figure 15. Average brightness of biocomposites filled with untreated and treated spelt husk fibers

microfibers (which decompose during plastic processing) led to an increase of brightness by approximately $10 \%$.

\section{Conclusions}

This research study has proven that grain by-products are a valuable source of lignocellulosic materials for microfiber processing. These can, in turn, be a substitute for wood flour in the production of thermoplastic biocomposites. One can conclude that only husks and hulls which contain lower amounts of fat, protein and starch are a good source for microfibers (Figure 3, 8-12). It has been shown that brans, which contain rests of grains, have more of these compounds, and, consequently, their biocomposites have inferior properties. In order to further improve their properties, an environmental friendly and selective processing with enzymes was proposed. Enzymatic treatment removed considerable amounts of starch, proteins and fats (Figure 3). Thus, the thermal stability of treated microfibers increased significantly (Figure 4). This, in turn, increased the brightness of the microfibers (Figure 14, 15), while simultaneously also leading to a decrease in odor in the composites (Figure 13). These features make the application of products made from biocomposites reinforced with microfibers from grain husks possible in household and automotive industries. The other aspect that shall be taken into account when using microfibers from grain by-products as reinforcement in WPC is their variable content of minerals, which is different depending on spices and varieties. In order to avoid faster wear of the processing equipment, namely the screws and barrels, only materials with lower mineral contents shall be selected (Figure 3). Therefore, 
the appropriate selection of husks and their proper processing to fibrous material, as well as their additional enzymatic treatment can produce valuable microfibers that may be used as an effective substitution of wood flour in WPC. This, in turn, is a solution for the shortage of precious wood. The obtained results show improvement in terms of mechanical properties (flexural and impact strengths) to previous researches concerning PP reinforced with microfibers from grain by-products [29].

In sum, the enzymatic treatment process led to the following changes in microfibers from grain husks and brans:

- a three-fold decrease of the starch content, 20$60 \%$ decrease of the protein content and 35-60\% decrease of content of fat,

- an increase of the thermal stability by about $20^{\circ} \mathrm{C}$ at $1 \mathrm{wt} \%$ loss,

- a 13-26\% improvement of the notched impact strength for their biocomposites,

- a 5-12\% increase of the heat deflection temperature for their biocomposites,

- a more than two-fold decrease of the odor emission for rye brans,

- a $10 \%$ increase of the brightness in biocomposites reinforced with microfibers from spelt husks.

\section{Acknowledgements}

The authors would like to express their appreciation to Novozymes, Univar Poland, Clariant Masterbatches, HSH Chemie Poland, JELU-WERK and the Institut für Lebensmittel- und Umweltforschung e. V. for supplying the enzymes, additives and reinforcing fibers. The authors would also like to thank Prachtgroup for the Arburg Allrounder 270 S 350100 injection molding machine. This research study was carried out in the context of the project 'Enzymatic Treatment of Natural Microfibers Applied in Biocomposites' grant no. 503-06-010-2617/4 funded by the National Science Center of Poland.

\section{References}

[1] Faruk O., Bledzki A. K., Fink H-P., Sain M.: Biocomposites reinforced with natural fibers: 2000-2010. Progress in Polymer Science, 37, 1552-1596 (2012). DOI: 10.1016/j.progpolymsci.2012.04.003

[2] Bledzki A. K., Sperber V., Theis S., Gassan J., Nishibori S.: Holzgefüllte Thermoplasteals Alternative für Naturholz. Gummi Fasern Kunststoffe, 52, 294-296 (1999).

[3] Reußmann T., Mieck P., Grützner R-E., Bayer R.: Recycling von Naturfaserverstärktem Polypropylen. Kunststoffe, 82, 80-84 (1999).
[4] Buongiorno J., Raunikar R., Zhu S.: Consequences of increasing bioenergy demand on wood and forests: An application of the global forest products model. Journal of Forest Economics, 17, 214-229 (2011). DOI: $10.1016 /$ j.jfe.2011.02.008

[5] Bledzki A. K., Gassan J.: Composites reinforced with cellulose based fibres. Progress in Polymer Science, 24, 221-274 (1999).

DOI: $10.1016 / \mathrm{S} 0079-6700(98) 00018-5$

[6] Faruk O., Bledzki A.: Wood plastic composite: Present and future. 'Wiley Encyclopaedia of Composites' (eds.: Nicolais L., Borzacchiello A., Lee S. M.) Wiley, vol 5, 3212-3232 (2012).

DOI: $10.1002 / 9781118097298 . w e o c 264$

[7] Steglitz H., Oswald P.: WPC market analyses report. Krauss Maffei, München (2011).

[8] Food and Agricultural Organization of the United Nations, Online database. http://faostat3.fao.org (2014).

[9] Oplinger E. S., Oelke E. A., Kaminski A. R., Kelling K. A., Doll J. D., Durgan B. R., Schuler R. T.: Alternative field crops manual - Spelt. University of Wisconsin, Wisconsin (1990).

[10] Neeson R.: Organic spelt production. Climate and water research - NSW Government industry and Investment (2011).

[11] Kumar A., Mohanta K., Kumar D., Parkash O.: Properties and industrial applications of rice husk: A review. International Journal of Emerging Technology and Advanced Engineering, 2, 86-90 (2012).

[12] Prasara J.: Comparative life cycle assessment of rice husk utilization in Thailand. PhD Thesis. RMIT University, Melbourne (2009).

[13] Sibakov J., Lehtinen P., Poutanen K.: Cereal brans as dietary fibre ingredients. 'Fibre-rich and wholegrain foods' (eds.: J. A. Delcour, K. Poutanen), Woodhead, Cambridge, 170-192 (2013).

DOI: $10.1533 / 9780857095787.2 .170$

[14] Valde Coerts T., Ossendorp B. C.: Fenitrothion. '2004 Joint FAO/WHO Meeting on Pesticides Residues. Rome, Italy', 173-174 (2005).

[15] Niir Board: Products from waste. National Institute of Industrial Research, New Delhi, 249-256 (2000).

[16] Tabak J.: Biofuels. Facts on File Inc., New York (2009).

[17] Narra S.: Bioenergy production: Special emphasis on rice husks usage in India. 'Implementing Environmental and Resource Management' (eds.: Schmidt M., Onyango V., Palekhov D.) Springer-Verlag, Berlin-Heidelberg, 15-22 (2011). DOI: $10.1007 / 978-3-540-77568-3$

[18] Novozymes: Cellulosic ethanol - Novozymes Cellic ${ }^{\circledR}$ HTec3 (application sheet). (2012).

[19] Merino S. T., Cherry J.: Progress and challenges in enzyme development for biomass utilization. Advances in Biochemical Engineering/Biotechnology, 108, 95120 (2007).

DOI: $10.1007 / 102007066$ 
[20] Teter S.: A closer look at the enzymes that deconstruct biomass. Novozymes, Bagsvaerd (2009).

[21] Bledzki A. K., Mamun A. A., Bonnia N. N., Ahmad S.: Basic properties of grain by-products and their viability in polypropylene composites. Industrial Crops and Products, 37, 427-434 (2012).

DOI: $10.1016 /$ j.indcrop.2011.05.010

[22] Bledzki A. K., Mamun A. A., Volk J.: Physical, chemical and surface properties of wheat husk, rye husk and soft wood and their polypropylene composites. Composites Part A: Applied Science and Manufacturing, 41, 480-488 (2010).

DOI: 10.1016/j.compositesa.2009.12.004

[23] Bledzki A. K., Mamun A. A., Volk J.: Barley husk and coconut shell reinforced polypropylene composites: The effect of fibre physical, chemical and surface properties. Composites Science and Technology, 70, 840846 (2010).

DOI: 10.1016/j.compscitech.2010.01.022

[24] Bledzki A. K., Mamun A. A., Jaszkiewicz A., Erdmann K.: Polypropylene composites with enzyme modified abaca fibre. Composites Science and Technology, 70, 854-860 (2010).

DOI: 10.1016/j.compscitech.2010.02.003

[25] Sharma H. S. S., Whiteside L., Kernaghan K.: Enzymatic treatment of flax fibre at the roving stage for production of wet-spun yarn. Enzyme and Microbial Technology, 37, 386-394 (2005).

DOI: $10.1016 /$ j.enzmictec.2004.10.007
[26] Nierstrasz V., Warmoeskeren M.: Process engineering and industrial enzyme applications. in 'Textile processing with enzymes' (eds.: Cavaco-Paulo A., Gübitz G. M.) Woodhead, Cambridge, 123-131 (2003).

[27] Gašparovič L., Koreňová Z., Jelemenský L.: Kinetic study of wood chips decomposition by TGA. Chemical Papers, 64, 174-181 (2010). DOI: $10.2478 / \mathrm{s} 11696-009-0109-4$

[28] Damhus T., Kaasgaard S., Lundquist H., Olsen H. S.: Enzymes at work. Novozymes, Bagsvaerd (2008).

[29] Mamun A. A., Bledzki A. K.: Micro fibre reinforced PLA and PP composites: Enzyme modification, mechanical and thermal properties. Composites Science and Technology, 78, 10-17 (2013). DOI: 10.1016/j.compscitech.2013.01.013

[30] Gómez-Martínez D., Barneto A. G., Martínez I., Partal P.: Modelling of pyrolysis and combustion of glutenglycerol-based bioplastics. Bioresource Technology, 102, 6246-6253 (2011).

DOI: 10.1016/j.biortech.2011.02.074

[31] Albis Plastic GmbH datasheets: Altech PP-H A 2040159 GF CP; and Altech PP-H A 2020100 GF20, Glass reinforced $\mathrm{PP}$ (2014). 